\section{Cómo enfrentar una epidemia respiratoria masiva, desde el punto de vista organizacional y un plan de contingencia}

\author{
How to face a massive respiratory epidemic, from the \\ organizational point of view and a contingency plan?
}

\author{
Dr. Eduardo Homero Ramírez-Segura,* Dr. Luis Gerardo Motta-Amézquita, ${ }^{\ddagger}$ \\ Mtra. Patricia Flores-Rojas, ${ }^{\S}$ Dra. Laura De Jesús-González"
}

RESUMEN. Las epidemias no son producto de la «globalización», han azotado a la humanidad desde sus orígenes, no hay que cerrar fronteras ni al turismo ni al comercio; en la antigüedad no había autopistas, trenes, trasatlánticos ni aviones y existían las epidemias, la historia demuestra que la protección real viene del intercambio de información científica confiable y de la solidaridad real; no obstante, en este mundo globalizado y comunicado, «era del punto com», se genera un sinnúmero de información día a día, incluso en minutos se publican cientos de artículos relacionados a la pandemia que hoy nos ocupa, el COVID-19, información que debemos saber seleccionar y discriminar adecuadamente para no perdernos en ella. Una vez entendido que el verdadero antídoto para una epidemia es la cooperación y no la segregación, se debe establecer un diagnóstico situacional, debemos trabajar al unísono, como un equipo con un mismo propósito, en este artículo pretendemos compartir el cómo organizarse desde el punto de vista logístico y cómo proteger y optimizar el valiosísimo recurso humano, el personal sanitario.

ABSTRACT. The epidemics are not a «globalization» product, this exists since the humanity begun, it's not necessary to close borders neither trade between countries, in the past did not exist highways, railway, tall ships or aircraft and the epidemics already existed, the history show and demonstrate us that the real protection is the interchange of confident information and the teamwork, we should work like global unity. In the global universe the information grow up exponentially daily, so we have to be careful with all the data that come to us. If we understand that an epidemic's antidote is the cooperation and unity, we should have the capacity to organize a solid teamwork based on a situational diagnose. Our purpose in this paper is to share our experience in organizational logistics and give its true value to health personnel.

Puedes ponerte en camino después que el enemigo y llegar antes, porque sabes cómo estimar y calcular las distancias.

El arte de la guerra. Sun Tzu

$\mathrm{L}$ as epidemias han azotado a la humanidad desde los orígenes de su historia, actualmente hay $\checkmark$ quien se ha atrevido a expresar que las pandemias son producto de la «globalización», por lo que habría que cerrar fronteras tanto al turismo como al comercio; no obstante, las epidemias se remontan a tiempos en los que ni siquiera había autopistas, trenes, trasatlánticos y mucho menos aviones, con estos últimos se pudiera propagar hoy día una epidemia transcontinental en menos de 24 horas. Desde la peste negra en el siglo XIV, las epidemias del siglo pasado (SIDA y Ébola) hasta las del presente Siglo XXI (H1N1, COVID-19) ${ }^{(1-3)}$, las pandemias han matado a un número menor de personas y no es porque los seres humanos tengan mejores defensas ante los agentes patógenos, aunado al aislamiento, sino por la fluidez de la información ${ }^{(4)}$.

No obstante, en este mundo globalizado y comunicado, «era del punto com», se genera un sinnúmero de información día a día, incluso en minutos, baste entrar a un buscador (Cochrane, PubMed, Medline, etcétera) bajo descriptores $\mathrm{MeSH}$ y nos arroja cientos de artículos relacionados con la pandemia que hoy nos ocupa, el COVID-19(1-3), información que debemos ser

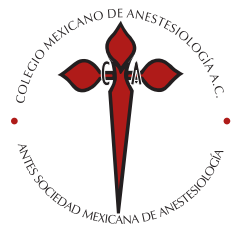

Palabras clave: COVID-19, liderazgo, logística, estrategia, epidemia.

Keywords:

COVID-19, leadership, logistics, strategy, epidemic.

* Médico Naval, Anestesiólogo y Neuroanestesiólogo. Academia Mexicana de Cirugía, Médico adscrito al Grupo Neuroquirúrgico Nave Medical, Ex Director de la Escuela de Postgrados en Sanidad Naval. Ex Jefe de División de Cirugía del Hospital Naval de Alta Especialidad.

‡ Médico Naval, Anestesiólogo y Anestesiólogo Pediatra. Médico adscrito de la Fundación Kardias. Subdirector de la Escuela de Postgrados en Sanidad Naval. Ex Jefe de División de Cirugía del Centro Médico Naval. $\S$ Enfermera Naval, Postgrado en Atención al Enfermo Crítico, Maestría en Docencia. Jefatura de Servicios Escolares. Escuela de Postgrados en Sanidad Naval. " Médico Naval, Maestría en Salud Pública. Jefatura de Estudios. Escuela de Postgrados en Sanidad Naval.

Secretaría de Marina-Armada de México. Ciudad de México.

Solicitud de sobretiros:

Dr. Eduardo Homero

Ramírez-Segura

E-mail: ehramseg@gmail.com

Recibido para publicación: 07-04-2020

Aceptado para publicación: 20-04-2020 
muy prudentes en seleccionar y discriminar adecuadamente para no perdernos en ella.

La historia nos ha demostrado que la protección real viene del intercambio de información científica confiable y de la solidaridad real; un precepto aprendido durante nuestra formación en el Army Medical Department Center and School, United States Health Readiness Center of Excellence, Fort Sam Houston, SA, Tx) del Ejército de los Estados Unidos de América, fue que se debe actuar y desempeñarse bajo el principio del trabajo en equipo, sin protagonismos (Army Medicine: One Team... One purpose), por lo que con este artículo pretendemos compartir el cómo organizarse desde el punto de vista logístico ante una contingencia, ya que podemos sentirnos rebasados y no sabemos cómo sistematizarnos y/o tomar el liderazgo, pensando en el bien común y respondiendo ciertos cuestionamientos: ¿cuál es el derrotero de la misión o encomienda?, ¿con qué elementos cuento?, ¿con quién voy a trabajar?, ¿qué debo hacer, cuál es mi función?, ¿cuál es el papel del líder o comandante?, ¿̇a quién le voy a rendir parte?

De primera instancia, ante una contingencia (desastre natural, epidemia, conflicto bélico), debemos establecer una estrategia desde el punto de vista logístico y organizacional, comenzando por hacer un diagnóstico situacional de los recursos humanos, materiales, infraestructura y financieros con los que contemos; una vez establecidos, analizar cuán preparado está el Recurso Humano en el tipo de contingencia a la que nos estamos enfrentando, con el fin de establecer cuáles son nuestros alcances y limitaciones. Esto con dos objetivos fundamentales: 1) que el personal con mayor experiencia (mas no la mayor jerarquía) dicte directivas y adiestre al de menor experiencia o habilidades en el problema en cuestión; 2) que se tomen las medidas de cuidado y precaución, dado que se infiere que este personal con menos familiaridad en la contingencia no sepa qué acciones tomar.

El activo más valioso de toda institución u organización, cualquiera que ésta sea, es el Recurso Humano, de modo que en el plan logístico se debe establecer que el personal de sanidad, cuando se trate de una contingencia sanitaria, es el recurso más valioso y al que se tiene que proteger de primera instancia, incluso antes que a la población objetivo. Siendo coloquiales, podemos hacer uso del adagio: «para que tu estés bien, yo debo estar bien», es decir, al personal se le debe proveer todo el equipo, materiales, insumos, infraestructura e incluso ambiente laboral y de condiciones de trabajo adecuados para responder con seguridad y eficacia ante una epidemia respiratoria masiva, pues no debemos perder de vista que ese personal de primer contacto ante la población también tiene familia y exactamente las mismas necesidades que la población susceptible.

Una vez entendido que el verdadero antídoto para una epidemia es la cooperación y no la segregación, y ya establecido el diagnóstico situacional, se debe organizar al personal tanto por sus características de liderazgo (Don de Mando) como por su formación profesional, se deben hacer grupos de trabajo, nombrar líderes y establecer roles, así como dictar procedimientos sistemáticos operativos (PSO) para trabajar en orden y de una manera homogénea, pero sobre todo sistematizada. Es muy importante que quien esté al mando sepa sustentar posicionamientos con base en sus capacidades y conocimientos y no se deje llevar por cuestiones políticas (no obstante a sabiendas que haya detrás decisiones o intereses políticos) ${ }^{(5,6)}$ ni protagonismos; asimismo, debe ser un líder moral y ver por su personal de una manera integral, dado que como se comentó en supra líneas, para que la población susceptible esté bien atendida, el recurso humano de sanidad debe contar con todo en todos los sentidos (equipo de protección personal, insumos, infraestructura, adecuados períodos y áreas de descanso, así como una correcta alimentación).

Una epidemia respiratoria masiva puede presentarse como una enfermedad leve, moderada o grave, con neumonía severa y síndrome de dificultad respiratoria aguda, por ello muchos de los hospitales se ven rebasados en todas sus capacidades y deben ser reservados para la atención de los pacientes con sintomatología de franca a estado grave, por lo que se deben establecer sedes alternas para el resguardo de pacientes potencialmente infectados llamados Centros de Aislamiento (CA), caracterizados muchas veces por no ser instalaciones con características propias de un hospital, éstos pueden ser dormitorios habilitados, barracas, carpas o casas de campaña móviles, hoteles, en fin, cualquier espacio habilitado con fines altruistas y de apoyo, pero siempre administrados, vigilados y organizados por personal sanitario.

Es recomendable establecer un sistema de pre-triaje (de preferencia en instalaciones situadas anexas o fuera del hospital), para establecer dos flujos de pacientes: 1) pacientes con fiebre y/o síntomas de infección respiratoria (pacientes posibles infectados) y 2) el resto de pacientes, para establecer quién se hospitaliza y quién se refiere al CA.

Los centros de aislamiento deben ser administrados bajo ciertos procesos (PSO) para no perder el control, toda vez que estos centros no son propiamente un hospital y se deben establecer muy bien sus reglas de operación. De primera instancia para «echar a andar» un CA se debe contar con ciertos insumos, por lo que el personal responsable del centro debe saber gestionar ante la instancia superior el suministro de material y equipo para el adecuado y correcto funcionamiento del centro (Tabla 1).

Es muy importante que el personal sanitario que se desempeñará en el CA conozca sus funciones específicas (Tabla 2).

El personal sanitario que brindará apoyo al personal susceptible de contagio deberá estar adecuadamente protegido con todo el equipo correspondiente (EPP) y deberá conocer el protocolo para su adecuada colocación y portación del mismo (Tabla 3).

Una vez realizado el pre-triaje como se indicó en párrafos anteriores, se debe establecer un PSO para la admisión del usuario al CA (Tabla 4). 
Tabla 1: Gestión y suministro de Insumos.

Proceso: Atención de usuarios en CA, con infección respiratoria masiva confirmado

Procedimiento: Gestión y suministro de insumos para atención de usuarios con infección respiratoria masiva

\begin{tabular}{|c|c|c|}
\hline Área & No. & Actividad \\
\hline Personal & 1 & Recaba las necesidades de material y equipo, para el funcionamiento del Centro de Aislamiento \\
\hline \multirow{20}{*}{$\begin{array}{l}\text { responsable del } \\
\text { CA }\end{array}$} & 2 & Solicita a la instancia sanitaria superior (ISS) el material necesario para la atención del usuario infectado: \\
\hline & & $\begin{array}{l}\text { a) Equipo de proteccion personal (EPP) } \\
\text { - Pijama quirúrgica de tela (camisa y pantalón) }\end{array}$ \\
\hline & & - Botas quirúrgicas desechables \\
\hline & & - Mascarillas N95 \\
\hline & & - Gafas de seguridad \\
\hline & & - Gorros quirúrgicos \\
\hline & & - Caretas de protección \\
\hline & & - Alcohol gel al $70 \%$ \\
\hline & & - Guantes quirúrgicos y/o de nitrilo \\
\hline & & - Batas quirúrgicas desechables: \\
\hline & & - Kit para usuario: \\
\hline & & - Jabón neutro líquido \\
\hline & & - Shampoo \\
\hline & & - Cepillo de dientes \\
\hline & & - Toalla de baño \\
\hline & & - Pasta dental \\
\hline & & - Papel higiénico \\
\hline & & - Sandalias \\
\hline & & b) Bolsas de RPBI (roja) \\
\hline & & c) Equipo médico: estetoscopio, baumanómetro, oxímetro de pulso, termómetro infrarrojo y cualquier otro equipo necesario \\
\hline $\begin{array}{l}\text { Responsable de } \\
\text { almacén }\end{array}$ & 3 & Recibe de la ISS el material solicitado y mediante inventario se concentra en el almacén correspondiente \\
\hline \multirow[t]{2}{*}{ Personal de apoyo } & 4 & Coordina con el responsable de cada turno el consumo del material y equipo utilizado \\
\hline & 5 & $\begin{array}{l}\text { Se encarga de surtir el stock del equipo de protección individual en el área destinada, a fin de evitar desabasto para los } \\
\text { diferentes turnos, registrándolo en el instrumento de control interno correspondiente }\end{array}$ \\
\hline $\begin{array}{l}\text { Responsable de } \\
\text { almacén }\end{array}$ & 6 & Proporciona los kits de usuario al responsable del filtro sanitario \\
\hline
\end{tabular}

$\mathrm{CA}=$ Centro de Aislamiento; $\mathrm{RPBI}$ = residuos peligrosos biológico-infecciosos; ISS = instancia sanitaria superior.

\section{Tabla 2: Funciones del personal sanitario en las salas del Centro de Aislamiento.}

Proceso: Atención de usuarios en CA, con infección respiratoria masiva confirmada

Procedimiento: Funciones del personal sanitario en las salas del CA

\begin{tabular}{|c|c|c|}
\hline Área & No. & Actividad \\
\hline \multirow{12}{*}{$\begin{array}{l}\text { Personal sanitario } \\
\text { en las salas } \\
\text { del Centro de } \\
\text { Aislamiento }\end{array}$} & 1 & Se presenta al área destinada previa colocación del equipo de protección designado (textil o desechable) descrito en la Tab/a 1 \\
\hline & 2 & Realizar la entrega-recepción de las áreas asignadas, así como los usuarios en aislamiento, según corresponda \\
\hline & 3 & Realizar rutina de sala según corresponda (médico-enfermero) \\
\hline & & a) Se presenta con los usuarios en aislamiento \\
\hline & & b) Verifica el estado de salud del usuario del CA \\
\hline & & c) Exploración física y medición de signos vitales (establecer frecuencia, según el estado físico) \\
\hline & & d) Realiza el registro de usuarios en aislamiento, altas y traslado a las unidades médicas correspondientes \\
\hline & & e) Realiza notas clínicas y de enfermería a usuario, asentar deterioro del estado de salud, si aplica el caso \\
\hline & 4 & Vigilar las medidas de protección estándar del personal de limpieza, lavandería y camareros. \\
\hline & 5 & $\begin{array}{l}\text { Coordinar con el responsable del almacén de material el abastecimiento de insumos para el lavado de vajilla de los usua- } \\
\text { rios en aislamiento (hipoclorito de sodio, detergente, fibra para tallado, contenedores para agua jabonosa, agua clorada, } \\
\text { así como escurridores, bolsas para desechos orgánicos e inorgánicos, etc.) }\end{array}$ \\
\hline & 6 & Coordinar con lavandería el abastecimiento de ropa de cama y para paciente \\
\hline & 7 & Fin de procedimiento \\
\hline
\end{tabular}


Tabla 3: Colocación del equipo de protección personal con bata.

Proceso: Atención de usuarios en CA con infección respiratoria masiva confirmada

\begin{tabular}{|c|c|c|}
\hline Área & No. & Actividad \\
\hline \multirow{3}{*}{$\begin{array}{l}\text { Personal sanitario que } \\
\text { tendrá contacto con } \\
\text { usuarios con infección } \\
\text { respiratoria masiva } \\
\text { confirmada. Varones, de } \\
\text { preferencia sin barba }\end{array}$} & \multicolumn{2}{|r|}{ Colocación del equipo de protección personal con bata } \\
\hline & 1 & Retirar accesorios, joyas, reloj, bolígrafos, celular \\
\hline & 2 & Trasladarse al área destinada para la colocación del equipo de protección personal \\
\hline Monitor u observador & 3 & Supervisar al personal sanitario durante todo el procedimiento bajo una rúbrica de cotejo \\
\hline \multirow{12}{*}{$\begin{array}{l}\text { Personal sanitario que } \\
\text { tendrá contacto con } \\
\text { usuarios con infección } \\
\text { respiratoria masiva } \\
\text { confirmada }\end{array}$} & 4 & Hacer una inspección visual para cerciorarse de la integridad de protección personal (EPP) y que sean del tamaño adecuado \\
\hline & 5 & Realizar higiene de manos con alcohol-gel al $70 \%$, durante 20 a 40 segundos \\
\hline & 6 & Colocar primer par de guantes, de preferencia de un color diferente a los guantes externos para que puedan ser visibles \\
\hline & 7 & Colocar gorro quirúrgico cubriendo orejas y cabello en su totalidad \\
\hline & 8 & $\begin{array}{l}\text { Colocar la mascarilla (N95) formando un sello hermético nariz-boca-barbilla y ajustar las tiras elásticas (inferior a nivel de la } \\
\text { nuca y por debajo de la inserción de las orejas) }\end{array}$ \\
\hline & 9 & $\begin{array}{l}\text { Colocar las gafas de seguridad cotejando el ajuste perfecto y que no interfieran con la visión ni con el adecuado sellado de } \\
\text { la mascarilla }\end{array}$ \\
\hline & 10 & Colocar las botas desechables cubriendo la totalidad de la superficie externa de los zapatos \\
\hline & 11 & $\begin{array}{l}\text { Verificar que la bata sea del tamaño adecuado y no deben recorrerse las mangas para dejar piel descubierta al estirar los } \\
\text { brazos, asimismo, debe ser lo suficientemente amplia como para cubrir su espalda }\left(360^{\circ}\right) \text { y al sujetar el nudo éste debe } \\
\text { quedar a un costado }\end{array}$ \\
\hline & 12 & Colocar la bata impermeable desechable y no estéril, con mangas largas \\
\hline & 13 & Colocar segundo par de guantes cubriendo los puños de la bata y sin que quede piel expuesta \\
\hline & 14 & $\begin{array}{l}\text { Levantar los brazos hacia los lados en un ángulo de } 90^{\circ} \text { y girar sobre su propio eje para que el supervisor verifique la } \\
\text { adecuada colocación del equipo de protección personal (EPP) }\end{array}$ \\
\hline & 15 & Evitar realizar ajustes del equipo de protección personal (EPP) mientras se encuentra en el área de atención del paciente \\
\hline
\end{tabular}

Tabla 4: Admisión del usuario a un Centro de Aislamiento.

Proceso: Atención de usuarios con infección respiratoria masiva confirmada

Procedimiento: Recepción del usuario en un CA con infección respiratoria masiva confirmada

\begin{tabular}{|c|c|c|}
\hline Área & No. & Actividad \\
\hline \multirow{9}{*}{$\begin{array}{l}\text { Personal responsable } \\
\text { del área de recepción }\end{array}$} & 1 & Recibe al usuario en la puerta principal del CA manteniendo un trato cordial y respetuoso a una distancia de 1.5 metros \\
\hline & 2 & $\begin{array}{l}\text { Solicita al usuario que muestre documento emitido por un laboratorio autorizado donde se indique resultado confirmado de } \\
\text { la infección respiratoria, así como una identificación oficial }\end{array}$ \\
\hline & 3 & $\begin{array}{l}\text { Realiza cuestionario para conocer si el usuario cumple con los requisitos de ingreso al CAV: } \\
\text { - Usuario con prueba de laboratorio positiva de COVID-19 }\end{array}$ \\
\hline & & $\begin{array}{l}\text { - No padecer padecimientos crónico-degenerativos agregados (hipertensión arterial, diabetes mellitus, tiroides) cáncer, } \\
\text { asma, inmunosupresión o psiquiátrico }\end{array}$ \\
\hline & & - Edad de 18 a 50 años \\
\hline & & - No antecedentes de consumo de psicotrópicos o drogas \\
\hline & 4 & Proporciona mascarilla facial al usuario en caso de que se presente sin ella \\
\hline & 5 & Proporciona alcohol-gel al $70 \%$ para la higiene de manos \\
\hline & 6 & Indica al usuario la ruta a seguir para llegar al área de filtro \\
\hline \multirow{2}{*}{$\begin{array}{l}\text { Personal responsable } \\
\text { del filtro sanitario }\end{array}$} & 7 & Registra al usuario en la hoja de control correspondiente y comunicará al médico en turno el arribo del usuario \\
\hline & 8 & Conduce al usuario al área de exploración manteniendo una distancia de 1.5 metros aproximadamente \\
\hline \multirow[t]{2}{*}{ Médico en turno } & 9 & $\begin{array}{l}\text { Realiza al usuario una exploración física y valoración del estado de salud de ingreso para corroborar que se encuen- } \\
\text { tra sin datos de enfermedad grave }\end{array}$ \\
\hline & 10 & $\begin{array}{l}\text { Proporciona al usuario el reglamento interno del CA, carta de deslinde de responsabilidades y consentimiento bajo informa- } \\
\text { ción para su conocimiento, los cuales deberán requisitar con firma autógrafa correspondiente }\end{array}$ \\
\hline \multirow[t]{4}{*}{ Enfermera en turno } & 11 & Proporciona al usuario kit de aseo personal y lo conduce al área de vestidor \\
\hline & 12 & $\begin{array}{l}\text { Verifica que el usuario se retire la ropa que lleve puesta y se coloque pijama y botas, depositando sus pertenencias en una } \\
\text { bolsa plástica }\end{array}$ \\
\hline & 13 & Conduce al usuario a la sala de aislamiento correspondiente \\
\hline & 14 & Fin del procedimiento \\
\hline
\end{tabular}




\section{Tabla 5: Reglamento para el usuario del Centro de Aislamiento.}

Reglamento para el usuario del centro de aislamiento

1. Apegarse y respetar las políticas internas de seguridad del CA, queda estrictamente prohibido fotografiar, filmar y/o grabar con medios propios con la finalidad de guardar la confidencialidad de los afectados

2. Antes del ingreso al Centro de Aislamiento deberá retirarse accesorios (joyas, aretes, reloj, pulseras, broches para el cabello), uñas o pestañas postizas, maquillaje

3. Mantener el orden, respeto y reglas de convivencia dentro del recinto

4. Firmar la hoja de consentimiento informado en donde exprese por escrito su autorización para ingresar a las instalaciones con motivo del aislamiento

5. Queda estrictamente prohibido introducir cualquier tipo de alimentos y/o bebidas no autorizadas

6. Consumir los alimentos en las áreas y horarios establecidos

7. Separar los residuos de alimentos en los contenedores destinados para basura orgánica e inorgánica

8. Será responsable de lavar los utensilios utilizados para la toma de sus alimentos

9. Mantener limpia y en orden el área asignada para su aislamiento y descanso

10. Permanecer en el área asignada para su atención, evitando desplazarse a otras salas de aislamiento

11. Respetar los horarios y espacios destinados para su aseo e higiene personal

12. Evitar dejar basura y residuos en las áreas de aseo personal (cabello, envolturas, rastrillos, jabón, entre otros)

13. Respetar la rutina de las actividades establecidas en el Centro de Aislamiento

14. Queda terminantemente prohibido manipular cualquier tipo de material o equipo médico instalado en las áreas de aislamiento y descanso

15. Abstenerse de escribir, dibujar, maltratar y/o dañar cualquier área o mueble del recinto

16. Seguir las medidas de seguridad de salud e higiene que le recomiende el personal sanitario

17. Conocer la localización y uso de las puertas de emergencia, así como los indicadores de Protección Civil en caso necesario

18. Será directamente responsable de sus objetos personales y de los dispositivos electrónicos autorizados (celular)

19. Las visitas estarán restringidas durante su estancia en este establecimiento

20. Acatar las indicaciones del personal de sanidad que reciba con base en la valoración médica que le realicen

21. En caso de infringir alguno de los puntos anteriormente descritos, el usuario se sujetará al procedimiento penal, civil, administrativo 0 disciplinario según corresponda e incluso la expulsión del Centro de Aislamiento

\section{Tabla 6: Manejo de alimentos para usuarios de un Centro de Aislamiento.}

Proceso: Atención de usuarios en CA con infección respiratoria masiva confirmada

Procedimiento: Entrega de alimentos a usuarios ${ }^{(7)}$

\begin{tabular}{|c|c|c|}
\hline Área & No. & Actividad \\
\hline Coordinador General & 1 & Elabora el estado de fuerza del personal admitido en el Centro de Aislamiento \\
\hline \multirow[t]{7}{*}{ Personal de cocina } & 2 & $\begin{array}{l}\text { Prepara los alimentos para el personal aislado conforme al estado de fuerza entregado por el Coordinador } \\
\text { General }\end{array}$ \\
\hline & 3 & $\begin{array}{l}\text { Dispone los alimentos para su traslado en el carrito de servicio de alimentos, con los contendedores y charolas } \\
\text { destinados para su ingreso al área de comedor de la zona de aislamiento }\end{array}$ \\
\hline & 4 & $\begin{array}{l}\text { Previo a su desplazamiento a la zona de aislamiento, debe realizar las medidas de protección sanitaria } \\
\text { siguientes: }\end{array}$ \\
\hline & & 1) Retiro de joyería de manos y muñecas \\
\hline & & 2) Lavado de manos conforme a la técnica establecida \\
\hline & & 3) Colocación de guantes de látex o nitrilo, cubre bocas convencional, bata desechable y gafas de seguridad \\
\hline & 5 & $\begin{array}{l}\text { Procede al traslado del carrito de servicio de alimentos hasta el límite de la zona de aislamiento (área de } \\
\text { transfer), donde serán depositadas las charolas con los contendores de alimentos }\end{array}$ \\
\hline \multirow[t]{3}{*}{ Personal usuario } & 6 & $\begin{array}{l}\text { Toma las charolas con los contendores de alimentos del área designada en el límite de la zona de aislamiento } \\
\text { (área de transfer) y procederá a su traslado al área de comedor }\end{array}$ \\
\hline & 7 & $\begin{array}{l}\text { Concluida la ingesta de alimentos, procederá a depositar los desechos alimentarios y basura en los sitios } \\
\text { designados, así como lavar su vajilla personal }\end{array}$ \\
\hline & 8 & Regresarán las charolas al carrito de servicio de alimentos \\
\hline \multirow[t]{3}{*}{ Personal de cocina } & 9 & $\begin{array}{l}\text { Con su equipo de protección personal, procederá a tomar el carrito de servicio de alimentos que se encuentra } \\
\text { en el límite de la zona de aislamiento (área de transfer) }\end{array}$ \\
\hline & 10 & $\begin{array}{l}\text { Procederá al lavado de las charolas y contendores de alimentos, así como la desinfección del carrito de } \\
\text { servicio de alimentos, considerando dicho material como infectado, por lo que deberá extremar medidas de } \\
\text { seguridad sanitaria, como el cambio de guantes }\end{array}$ \\
\hline & 11 & Fin del procedimiento \\
\hline
\end{tabular}


Tabla 7: Traslado a unidad hospitalaria.

Proceso: Atención de usuarios en CA con infección respiratoria masiva confirmada

Procedimiento: Traslado de un usuario grave y/o complicado con infección respiratoria masiva confirmada por sistema médico de emergencias (SME) a un Centro de Atención Médica de acuerdo con las Guías OMS, CDC y NOM

\begin{tabular}{|c|c|c|}
\hline Área & No. & Actividad \\
\hline & & $\begin{array}{l}\text { Si un usuario con datos de deterioro del estado de salud por infección respiratoria masiva confirmada (positivo) } \\
\text { requiera traslado a un centro hospitalario para una evaluación y manejo intensivo, se deberán considerar las } \\
\text { siguientes acciones por parte del personal sanitario del CA y todo aquel que participe en el traslado }\end{array}$ \\
\hline Coordinador General & 1 & $\begin{array}{l}\text { Verificar que el personal de salud responsable del traslado del usuario, cuente con el EPP adecuado; asimismo, el } \\
\text { usuario cuente en todo momento con mascarilla quirúrgica }\end{array}$ \\
\hline \multirow{2}{*}{ Trabajo social } & 2 & Coordinará vía telefónica con el escalón médico receptor para el traslado del usuario \\
\hline & 3 & Notificar a la familia el estado de salud del usuario y el hospital al que será trasladado \\
\hline $\begin{array}{l}\text { Médico, enfermería, camillero } \\
\text { y chofer }\end{array}$ & 4 & $\begin{array}{l}\text { El transporte del usuario se realizará en una ambulancia con la cabina del conductor físicamente separada del } \\
\text { área del transporte del usuario }\end{array}$ \\
\hline Enfermero y camillero & 5 & $\begin{array}{l}\text { El personal que intervenga en el transporte deberá ser informado previamente y deberá utilizar EPP adecuado } \\
\text { para la prevención de infección por microorganismos transmitidos por gotas y contacto }\end{array}$ \\
\hline Médico & 6 & $\begin{array}{l}\text { Verificar que, durante el transporte, la ventilación del vehículo en ambos compartimientos debe estar en modo no re- } \\
\text { circulado para maximizar los cambios de aire que reducen las partículas potencialmente infecciosas en el vehículo }\end{array}$ \\
\hline Enfermería, camillero y chofer & 7 & $\begin{array}{l}\text { Utilizar camilla exclusiva (modificada) de traslado para infección respiratoria confirmada y monitorización continua } \\
\text { de signos vitales }\end{array}$ \\
\hline Médico & 8 & Realizar la entrega del usuario con su hoja de referencia clínica actualizada al centro hospitalario receptor \\
\hline \multirow[t]{2}{*}{ Camillero y chofer } & 9 & $\begin{array}{l}\text { Deberán seguir los protocolos de descontaminación, mantenimiento y eliminación de residuos utilizados para dis- } \\
\text { minuir el riesgo de propagación y mecanismo de transmisión. El interior del vehículo será limpiado posteriormente } \\
\text { con una solución de hipoclorito al } 1 \% \text { o gel desinfectante aprobado para las superficies y se desechará el material } \\
\text { utilizado en el contenedor apropiado como residuo biológico }\end{array}$ \\
\hline & 10 & Fin del procedimiento \\
\hline
\end{tabular}

Tabla 8: Alta de un Centro de Aislamiento.

Proceso: Atención de usuarios en CA con infección respiratoria masiva confirmada

Procedimiento: Alta del usuario confirmado al término de los catorce días de aislamiento, en caso de estar asintomático

\begin{tabular}{lll}
\hline Área & No. & Actividad \\
\hline Personal médico & 1 & $\begin{array}{l}\text { Al término de los } 14 \text { días de haber permanecido en el Centro de Aislamiento y haber cursado estable y sin datos } \\
\text { de deterioro de su estado de salud, el será dado de alta } \\
\text { Explicar al usuario todo lo relacionado sobre su padecimiento, así como los cuidados que deberá aplicar en su } \\
\text { domicilio }\end{array}$ \\
Personal de enfermería & 2 & $\begin{array}{l}\text { Registrar el alta en el formato, libreta o base de datos correspondiente } \\
\text { Informar a Trabajo Social el alta médica del usuario }\end{array}$ \\
Trabajo Social & 3 & Informar a la Dirección de Sanidad Naval el alta del usuario \\
Personal de enfermería & 4 & Trasladar al usuario al área asignada para el cambio de pijama quirúrgica por ropa de calle \\
Personal de apoyo & 6 & Acompañar al usuario a la puerta de egreso \\
& 7 & Fin del procedimiento
\end{tabular}

El usuario de un Centro de Aislamiento tiene la obligación de sujetarse a las reglas internas del recinto, por lo que deberá conocer, respetar y firmar un reglamento (Tabla 5).

El adecuado manejo de los alimentos que se provean en el Centro de Aislamiento es vital para el buen funcionamiento del mismo, así como para la satisfactoria evolución de los usuarios. Es por ello que se debe elaborar un PSO para su administración (Tabla 6).
Si algún usuario de un CA evoluciona hacia el deterioro o agravamiento de la enfermedad, éste debe ser referido a un centro hospitalario que cuente con los recursos humanos, materiales y de infraestructura para ser atendido adecuadamente, para ello también es necesario cumplir con un protocolo basado en un PSO (Tabla 7).

Una vez que el usuario ha evolucionado satisfactoriamente, se debe programar su alta del CA, pero siempre siguiendo un protocolo (Tabla 8). 
Tabla 9: Funciones de Trabajo Social.

Proceso: Atención de usuarios en CA con infección respiratoria masiva confirmada

Procedimiento: Gestiones de Trabajo Social en el Centro de Aislamiento de usuarios confirmados

\begin{tabular}{lll}
\hline Área & No. & Actividad \\
\hline Trabajo Social & 1 & $\begin{array}{l}\text { Verificar el llenado de cédula de identificación y registro interno para control de usuarios en el CA, de acuerdo con el formato } \\
\text { establecido (se debe formular un formato de acuerdo con cada institución) } \\
\text { Verificar derechohabiencia a instituciones de salud (IMSS, ISSSTE, SSA, PEMEX, SEDENA, SEMAR, PRIVADO, etcétera) } \\
\end{array}$ \\
2 & $\begin{array}{l}\text { Establecer contacto con su dependencia e informar que se tiene un derechohabiente en el CA } \\
\text { Realizar censo diario de usuarios con infección respiratoria masiva confirmado que ingresan al CA y remitir novedades al coordi- } \\
\text { nador del CA en turno }\end{array}$ \\
4 & $\begin{array}{l}\text { Brindar información a los familiares del usuario en horarios establecidos por el Coordinador General } \\
\text { Gestionar el traslado a centros de atención médica receptores para usuarios complicados, conforme a las indicaciones del } \\
\text { Coordinador General } \\
\text { Fin de procedimiento }\end{array}$
\end{tabular}

Tabla 10: Acceso del personal sanitario al Centro de Aislamiento.

Proceso: Atención de usuarios en CA con infección respiratoria masiva confirmada

Procedimiento: Acceso del personal sanitario (médicos y enfermeras) que brindará atención a usuarios con infección respiratoria masiva confirmada

\begin{tabular}{|c|c|c|}
\hline Área & No. & Actividad \\
\hline Personal de Sanidad & 1 & Accesar por el área designada en el Centro de Aislamiento para iniciar su turno \\
\hline \multirow{6}{*}{$\begin{array}{l}\text { Se sugiere no utilizar barba, ya que } \\
\text { los virus pueden permanecer en ella } \\
\text { por más tiempo, aunado a que las } \\
\text { mascarillas no sellan adecuadamente } \\
\text { con la cara }\end{array}$} & 2 & $\begin{array}{l}\text { Realizar el cambio de ropa (de civil, uniforme, de calle) que porte, por el uniforme quirúrgico desechable o } \\
\text { de uso exclusivo para las áreas de atención a usuarios con infección respiratoria masiva confirmada }\end{array}$ \\
\hline & 3 & $\begin{array}{l}\text { Vestir con el Equipo de Protección Personal (EPP) que corresponda de acuerdo con su área de trabajo, con } \\
\text { la secuencia de colocación del mismo, descrito en la Tabla } 3\end{array}$ \\
\hline & 4 & $\begin{array}{l}\text { Ingresar por las áreas indicadas hasta la zona de atención del manejo de usuarios con infección respirato- } \\
\text { ria masiva confirmada }\end{array}$ \\
\hline & 5 & Permanecer en sus áreas de trabajo de acuerdo al horario estipulado por la autoridad de la unidad \\
\hline & 6 & $\begin{array}{l}\text { La salida del personal deberá ser con el orden inverso a su acceso, debiendo desechar la ropa si fuera des- } \\
\text { echable, en caso de no serlo, darle el tratamiento correspondiente con el servicio de lavandería }\end{array}$ \\
\hline & 7 & $\begin{array}{l}\text { Todo el personal sanitario que labore en el CA deberá bañarse y cambiarse ropa limpia antes de retirarse a } \\
\text { su domicilio }\end{array}$ \\
\hline
\end{tabular}

El trabajo de un auxiliar muy importante de los servicios sanitarios es sin duda el servicio logístico del personal de Trabajo Social, quienes realizan una importantísima labor al ser el enlace entre el usuario, sus familiares, el equipo sanitario y los centros hospitalarios, es por ello que también su labor se debe llevar a cabo bajo un PSO (Tabla 9).

Un procedimiento muy importante en el proceso y logística de cómo enfrentar una epidemia respiratoria masiva es el cuidado del personal sanitario, ya que como ha sido interés desde la planificación, es el recurso más importante de toda institución, por lo que se debe dictar un PSO para su acceso y abandono de las instalaciones consideradas como contaminadas (Tabla 10).
El manejo de la ropa, tanto de cama como la utilizada por los usuarios de un centro de aislamiento, debe hacerse bajo un PSO ya que puede ser un fómite y debe ser manejada bajo un proceso especial (Tabla 11).

Al final de la jornada, se debe hacer un «recuento de daños», una autoevaluación crítica y objetiva (debriefing) con el fin de sacar provecho a las lecciones aprendidas de los errores; es importante que todos los miembros del equipo participen, incluso de manera anónima para evitar sesgos o represalias, dado que los líderes muchas veces no se enteran más allá de los reportes que reciben, ajenos totalmente a lo que se vivió verdaderamente en el «campo de batalla», de modo que esto enriquece al analizar las fortalezas, debilidades, amenazas y coyunturas, brindando la ocasión de incidir en las áreas de 
Tabla 11: Manejo de ropa contaminada.

Proceso: Atención de usuarios en CA con infección respiratoria masiva confirmada

Procedimiento: Entrega-recepción de ropa de cama al servicio de lavandería del Centro de Aislamiento

\begin{tabular}{lcl}
\hline Área & No. & Actividad \\
\hline Personal de usuarios & 1 & $\begin{array}{l}\text { Cuando se traslade a otra sala o fuera del CA, procederá a retirar y doblar su ropa de cama sin sacudir dicha ropa } \\
\text { durante el proceso, con el fin de no generar aerosoles y depositarla en la bolsa de seguridad correspondiente. Este } \\
\text { material será considerado como infectado }\end{array}$ \\
$\begin{array}{l}\text { Personal de alojamiento sin } \\
\text { contacto con pacientes }\end{array}$ & 2 & $\begin{array}{l}\text { Procederá a retirar las bolsas de seguridad con ropa de cama de usuarios infectados confirmados, debiendo rotularla } \\
\text { con el diagnóstico para su correcto proceso }\end{array}$ \\
Personal de lavandería & 3 & $\begin{array}{l}\text { Coordinar el traslado de la ropa de cama de los usuarios del CA a la lavandería } \\
\text { Procederá a realizar las medidas de protección sanitaria siguientes: }\end{array}$ \\
& 4 & $\begin{array}{l}\text { Retiro de joyería de manos y muñecas } \\
\text { - Lavado de manos con gel conforme a la técnica establecida } \\
\text { Colocación de guantes de hule, mascarilla facial convencional, mandil de plástico y gafas de seguridad }\end{array}$ \\
& 5 & $\begin{array}{l}\text { Recibirá en el transfer de la zona de aislamiento las bolsas de seguridad con ropa de cama de los usuarios del CA } \\
\text { Procederá a rotular el contenedor especificando su contenido, número y área de procedencia }\end{array}$ \\
& 7 & $\begin{array}{l}\text { Procederá a trasladar el contenedor al área de lavandería para realizar el lavado correspondiente } \\
\text { Procederá a realizar el lavado de la ropa de cama con los cuidados necesarios para el lavado de ropa contaminada } \\
\text { La entrega de la ropa de cama limpia será en el área de transfer al personal de apoyo }\end{array}$ \\
& 9 & Trasladará la ropa de cama limpia a la zona de aislamiento
\end{tabular}

oportunidad identificadas, siempre en aras de una mejora; este tipo de contingencias, dado que nos sacan de nuestra «área de confort», son ambientes estresantes, la carga de trabajo es demandante y agitada, un constante ir y venir, llamadas telefónicas, partes de novedades, nuevas admisiones, altas, evoluciones tórpidas, traslados, conversaciones, informes de otros centros de aislamiento y hospitales comentando sus complicaciones, etcétera, por lo que se debe ser flexible y comprensivo como líder, teniendo siempre presente que el éxito de una misión se basa en la organización, planteamiento de estrategias y sistematización de los procesos, así como en el trabajo en equipo, sin importarnos como personal sanitario que existan decisiones políticas detrás ${ }^{(5)}$.

Estas mismas estrategias y sistematización de los procedimientos se deben emplear en cada una de las áreas hospitalarias, pero principalmente en las áreas críticas que son las que principalmente atenderán pacientes potencialmente infectados o confirmados de una epidemia respiratoria masiva (quirófanos, unidades de cuidados intensivos, urgencias, por mencionar algunas), se debe realizar un PSO de cada proceso con miras a automatizar la sistematización bajo el principio que lo que se realiza bajo estos conceptos tiende a tener menor margen de error; asimismo, se deberá establecer una estrategia por ejemplo para la cirugía electiva, ya las sociedades médicas y colegios de cada especialidad han dictado criterios para clasificar las urgencias reales y actuar en el momento indicado con todas las medidas de seguridad, tanto para el personal médico como para los pacientes, y de esta manera optimizar el eventual uso de las áreas como unidades de recuperación postanestésica, preoperatorio, cuidados intermedios, etcétera, como potenciales áreas de atención a pacientes infectados confirmados.

\section{REFERENCIAS}

1. OMS. Disponible en: https://www.who.int/emergencies/diseases/novel/ coronavirus-2019/technical-guidance/early-investigations

2. Secretaría de Salud. Manual de Proceso de Prevención de Infecciones para las personas con COVID-19 (enfermedad por SARS-CoV-2), contactos y personal de salud.

3. Secretaría de Salud. Lineamiento estandarizado para la vigilancia epidemiológica y por laboratorio de COVID-19.

4. Noah HY. El País. Marzo. 2020.
5. Zinni T. Before the first shots are fired. Ed. St. Martin's Griffin. NY. Sept. 2015.

6. Hennessy K. US A Legacy of Lessons Learned: during wartime. Army Medical Department Center and School. Health Readiness Center of Excellence. Ed. Superintendent of Documents, US Goverment Publishing Office. 2016.

7. Norma Oficial NOM-251-SSA1-2009, Prácticas de higiene para el manejo de alimentos, bebidas o suplementos alimenticios. 